\title{
Physical and Virtual Environment for Automation Education of Engineers and Technicians Part 1: Engineering an Automated Recycling Facility for Bottles and Cans
}

\author{
Jean Brousseau, Professor, UQAR \\ Denis Paradis, Professor, Cégep de Rivière-du-Loup \\ Abderrazak ElOuafi, Professor, UQAR \\ Suzie Loubert, Research Assistant, UQAR \\ Email contact: Jean_Brousseau@uqar.qc.ca and denpar@cegep-rdl.qc.ca
}

\begin{abstract}
Nowadays, production equipments are controlled by programmable logic controllers (PLC) that can communicate over Ethernet. The technicians and engineers of the industry work together in order to develop, support, diagnose, solve, and optimize automated production systems. Current technology has attained such a level of sophistication that it is now possible to interact with a machine without having to move from ones chair.

Faced by these observations, the Université du Québec à Rimouski(UQAR), the Cégep de Rivière-duLoup, and Premier Tech Company, a world leader in the field of bagging equipment, have decided to join forces in order to improve the training of future engineers and technicians in the field of Industrial Automation and Control. The aim of the project is to allow university and CEGEP (college) students to work together on practical problems while being in two separate sites. The first step consists of designing an automated mini plant for the recycling of containers. The mini plant, designed and manufactured by UQAR's engineering students, has been installed in the CEGEP building located $100 \mathrm{~km}$ away from the University. The aim of the following step is to create a virtual environment allowing the follow up and visualization of the mini plant, to diagnose problems from a remote location, etc. Finally, the project focus on the development of training situation scenarios related to breakdown diagnostics, parameter adjustments, performance tests, security aspects, and process optimization.

This article offers an overview of the project and of the mini plant as designed by the engineering students of UQAR.
\end{abstract}

\section{Introduction}

Today's manufacturing processes are highly automated. Each machine is now controlled by an industrial programmable logic controller that commands the sequence of operations and allows for the automation and closed-loop control of the processes. Each machine is linked with other machines via a network that allows them to communicate. Each unit of equipment can be remotely accessed for operation management and diagnostic purposes. However the networking of all equipments increases the complexity of automated systems and unavoidably introduces computer security issues.

Throughout the industry, technicians and engineers join forces to develop, support, optimize and diagnose production systems at the core of which automation occupies a forever increasing important place. Once the equipment is sold and installed at the clients', engineers and technicians must often, remotely or on site, solution automation issues. Today's technology has reached such a level of sophistication that, directly from their office, responders can consult a large bank of data that allows them to assess the operation of any equipment installed anywhere in the world via a virtual interface. They can monitor the operation of a device, adjust its working configuration, do tests and fix many problems without having to move from their office. In one word, everything can be implemented to reduce costs and offer the best possible service to the client.

Although engineers and technicians of the industry work together, their training is rather done independently. The main objective of this project is to allow both teaching orders to come closer by the implementation of a joint training context for the domain of automation. The idea is to allow students 
and teachers from the university and the technical college to experience joint training situations.

\section{Context at the technical college}

At the 2007 Fall Semester, the Département de technologie de l'électronique industrielle (DTÉI) (Industrial Electronic Technology Department) begins the implementation of its new Industrial Electronics Program that merges the electrodynamics, instrumentation and automation. The problem-based and project-based approaches were selected for this new program.

In this particular context, the department wanted to use a complete automated system that would cover the many fields of speciality of its program. Such a system should prove to be more than a simple process simulator for educational purposes and should offer realistic situations.

To satisfy the exigencies of the new technical program, the new training facilities should allow students to develop their skills in the fields of electrical wiring of control panels, motors, sensors, etc., machine adjustment, pneumatic and hydraulic, advanced PLC programming, operator interface development, maintenance and servicing, industrial networking, security of automatic systems and open and closed loop controllers tuning.

Considering the Cégep de Rivière-du-Loup had recently obtained its Green College Certification, the idea of a system being able to process recyclable containers become the obvious solution. Such a system had to be designed and manufactured for the special needs of the Technical Program in Industrial Electronics.

\section{Context at the university}

On its part, the Université du Québec à Rimouski (UQAR) offers Bachelor Degrees in Mechanical Engineering, Electrical Engineering and Electromechanical Systems Engineering. In each program, automation occupies a important place. However, technical developments move ahead so rapidly that training for the control and automation sectors represents an immense pedagogical challenge. The engineer of the future, while he understands the mathematical and theoretical basics of automation, must also remain conversant with the rapid evolution of the technology. If the academic world of the university is well adapted to a more theoretical and basic type of instruction, the same cannot be said about its capability to put the students in real contact with practical work and current technologies. Professors must constantly keep up to date and ideally remain in contact with the industry in order to remain aware of the problems that engineers have to face.

\section{Objectives of the Project}

Considering these findings, the Engineering Department at UQAR, the DTÉI at the Cégep de Rivière-du-Loup and the industrial partner Premier Tech have decided to join forces to create a training environment where future engineers and technicians will be able to work together to solve practical problems similar to those encountered during their professional practice. In order to facilitate relations between the students of both emplacements and of both orders of teaching, university students at UQAR will have access to a virtual environment allowing them to follow the operations of the physical environment located at the Cégep de Rivière-du-Loup.

\section{Student's Objectives}

The project will allow students to be exposed to practical situations related to real life conditions of the industry. The students will be confronted to technical problems with concrete situations totally pertinent to the future trade. In addition to that, the exchanges between futures engineers and technicians will allow them to learn how to communicate and work together, and to respect the proficiency of the various professionals that rally around them. Indeed, engineers and technicians in the industry constantly share thoughts and experiences to solve problems.

\section{Professor's Objectives}

The physical and virtual environment will represent a real occasion to share and develop expertise, and to explore new pedagogical approaches. For the institutions, this project will allow them to encourage the synergy between the various professorial resources and to set necessary gateways between the Technical Program in Industrial Electronics and the various Bachelor Degrees in Engineering at UQAR.

\section{Partner's Objective}

For our partner, this project will allow him access to a labour force that is better prepared to face the challenges offered by the industry. On the other hand, within the framework of the partnership agreement between Premier Tech and the Cégep de Rivière-duLoup, the company's employees will be allowed to use 
the mini-plant for training and occupational upgrading purposes.

\section{Project Overview}

This project will be achieved in four phases spanning over a four year period. It will allow the students of two orders of teaching to be exposed to a state of the art environment.

The first phase consisted of developing the miniplant. This was a perfect mandate for engineering students attending the project-based design courses. Two years were required to complete the task.

For the second phase, the project team will set up the virtual environment allowing interactions between the students of the two sites and between the students and the mini-plant. In the second phase, the team will develop and experiment learning situations and teaching activities, measure the satisfaction level of the students and will pose a critical eye upon the completed work and the skills developed by the students. During this second phase, our industrial partner's cooperation will be of the upmost importance. His recommendations and expertise will prove an invaluable support as they will allow us to replicate the various environments required for the technicians and professional engineers to evolve.

For phase 3, the virtual learning environment and the learning activities developed during phase 2 will be enhanced. New learning scenarios will be proposed. Supported by our industrial partner, phases 2 and 3 will allow the team members from university and CEGEP to share technical and pedagogical expertises and skills.

Ultimately, phase 4 will allow us to put the finishing touches to the project. During this period, all the obtained background for the project will be documented in order to ensure its continuity and the sharing of the acquired experience.

\section{Target Courses and Learning Activities}

Within its three engineering programs, UQAR extensively covers the subject of automation. The three main courses targeted by the project are: Servo Control, Industrial Automation and Automated Production Systems. The targeted learning activities may be based on the diagnosis of breakdowns at the mini-plant, the "tune-up" of certain parameters, performance tests, security aspects and on process optimization.

At the Cégep de Rivière du-Loup, many courses offered through the Industrial Electronics Program are directly targeted by this project. Each fall semester, the final year students will familiarize themselves with the various sections of the mini-plant and will program the PLC and develop the user interfaces required for their proper operation. During the winter session, they will put all these sections together to make the miniplant fully operational. At this time, all aspects of the automated systems' security will be implemented.

The labs will allow the remotely located UQAR students and the CEGEP students to work together on various problems related to automation and control of the mini-plant's operation.

\section{Mini-plant for the Recycling of Containers}

The mini-plant is a system for the recycling of containers dedicated to training and used by the staff and the students of the CEGEP. For such a system and each module, the implemented technical solutions must be pedagogically profitable, rather than optimized for performance or costs.

The mini-plant will process two types of recyclable containers: pop cans and plastic bottles. It combines six different units: washing, stocking, sorting, can compaction, bottle shredding and, weighing and bagging. Each unit will have its own PLC and shall be able to be put on line and operated on a self-sustained basis. The different sections will then be linked as a whole.

For each unit, the mandate entrusted to the student teams consisted of designing and manufacturing a full and working prototype of one of the units. The development project of the mini-plant is defined in a book of specifications that contains the data and general restrictions for the project, a block diagram of the mini-plant and the technical data particular to each unit.

In addition to the working prototype, the deliverables required by the client were: the design report, drawings and specifications, the virtual model set, the project book containing all the pertinent information related to the unit and the final report including operating instructions, a maintenance program, a part list and test results.

The most important data and restrictions for the mini-plant are:

\section{Supplies}

Power: 120/208 V 3 Ø 100 A;

Pneumatic: 90 psi max with regulator; and

Water: $3 / 4$ in. conduit connected to city water main. 


\section{Machinery Security}

The mini-plant must meet the Machine Security Standards requirements. However, and whenever possible, safety guards must be made of clear plastic to allow viewing inside of the equipment.

\section{Control and Electrical Materials}

Material must be selected from the client's list of suppliers but the following must be ensured:

- The industrial programmable logic controllers must be of the Allen-Bradley type, CompactLogix series. They shall be fitted with 24 $\mathrm{V}$ dc input and output modules.

- If it becomes necessary to control the speed of a motor, POWERFLEX 40P electronic drives are required along with an Ethernet communication interface.

- All $24 \mathrm{~V}$ dc on/off control sensors and all machinery security devices must be of the OMRON type.

- Pneumatic equipment components required shall be of the FESTO type.

The units of the mini-plant are:

The Container Washer and Dryer Unit - washes the inside and outside of the container. It is paramount that the container be useable once it comes out of the washer. Loading of the washer will be done manually: meaning that an attendant will be required to insert the containers into the machine one at a time.

The Storage Unit - containers are deposited into the storage unit once they come out of the washer. It feeds the sorting unit automatically.

The Sorting Unit - by reading each container's code bar, the sorting unit directs them to the compacting unit or the bottle processing unit. The latter recognizes returnable and non returnable bottles. Returnable bottles are rejected from the system. They will be sold as such.

The Container Pressing Unit - this unit compacts the cans.

The Bottle Shredder Unit - first, this unit removes the label then shreds the plastic bottles.

The Classification Unit - the function of this unit is more pedagogical. Cans are classified according to their barcode information.

\section{Prototype}

The design and manufacturing project of the miniplant is almost completed. The washing and shredding units are presently into production and will be delivered in August and December of 2009 respectively. Figure 1 offers an overview of the miniplant in its present state.

\section{Conclusion}

The impact of this project will promote in practical terms the synergy that already exists between both establishments. This project will allow us to offer training that is concentrated on the needs of the industry and to better prepare our future professionals so that they can play their role in a proper manner. The facilities that have been installed, the educational activities that will be developed and the ties between the various contributors from both institutions will allow this collaboration to endure and to continue to improve the training of future engineers and technicians. Already, the undergraduate engineering students involved in the project have been able to acquire a rather interesting design experience. They have had the chance to interact with a client and to produce a live system that will deliver concrete spinoffs for the training of future technicians and engineers.

Such a synergy between both orders of teaching will have an important impact on the quality of the training and on the retention of younger students. It allows for the revitalization of the training centres and the promotion of recruiting in this particularly neuralgic sector of the manufacturing industry. By their contact with engineering students of the university, some college students will thus develop the idea of continuing their studies in engineering at the university. On the other hand, the virtual environment will prove to be an extraordinary showcase to introduce our various programs. As far as we know, a network of this nature, associating a technical program, a university engineering program and an industrial partner does not exist anywhere else. The project will lead to concrete and innovative pedagogical changes. Every year, approximately 30 university students and the same amount of CEGEP students will team up to work on their lab assignments. 


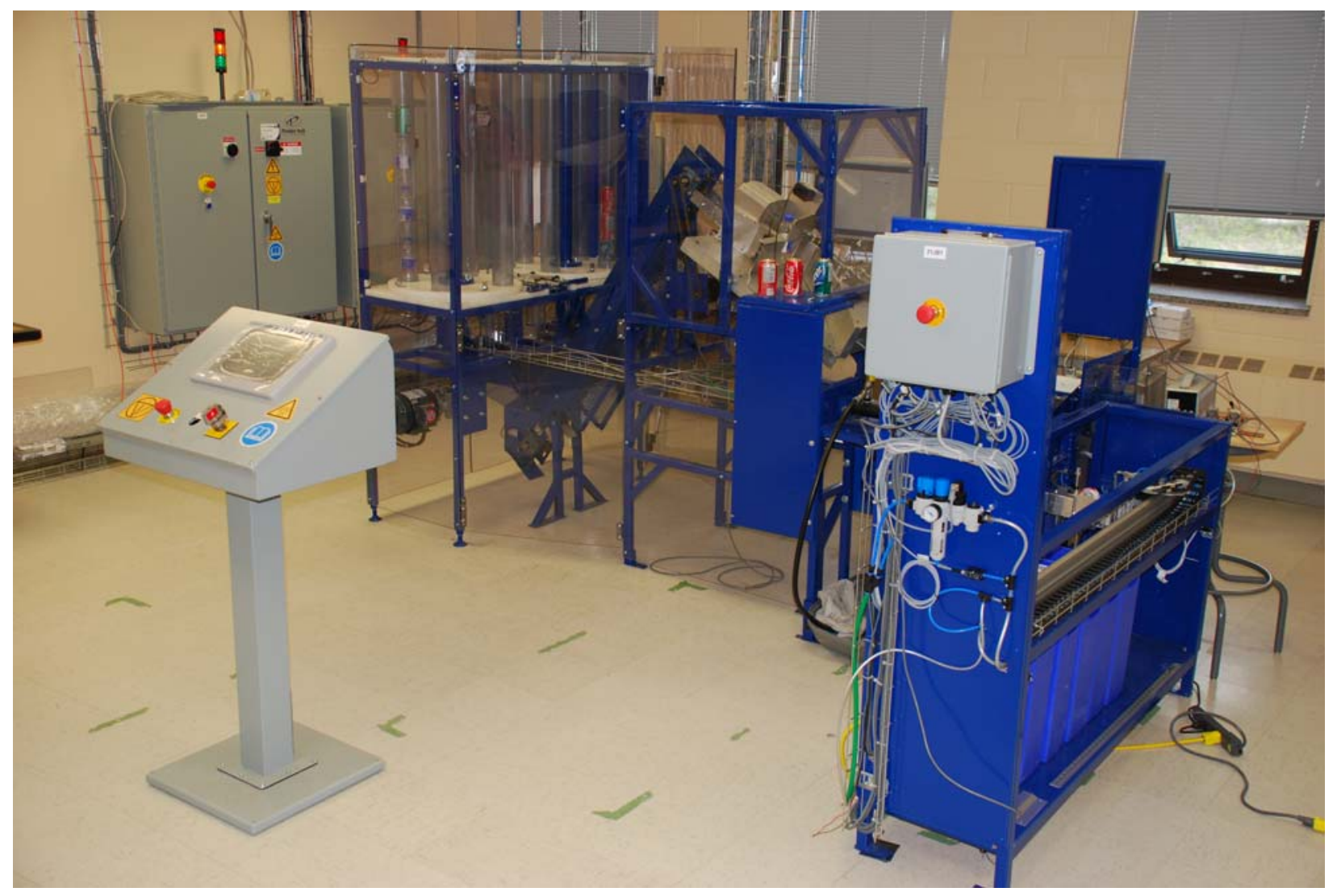

Figure 1 - Mini-plant for the recycling of cans and bottles 